05,13

\title{
Температурная зависимость напряжения, вызванного спиновым током в гетероструктуре манганит/иридат
}

\author{
(ㄱ Т.А. Шайхулов, К.Л. Станкевич, К.И. Константинян, В.В. Демидов, Г.А. Овсянников
}

Институт радиотехники и электроники им. В.А. Котельникова РАН,

Москва, Россия

E-mail: shcaihulov@hitech.cplire.ru

Поступила в Редакцию 9 апреля 2021 г.

В окончательной редакции 9 апреля 2021 г.

Принята к публикации 19 апреля 2021 г.

\begin{abstract}
Температурная зависимость напряжения, вызванного спиновым током, была исследована в эпитаксиальной тонкопленочной гетероструктуре $\mathrm{La}_{0.7} \mathrm{Sr}_{0.3} \mathrm{MnO}_{3} / \mathrm{SrIrO}_{3}$, напыленной на монокристалическую подложку $\mathrm{NdGaO}_{3}$. Спиновый ток генерировался при СВЧ воздействии в условиях ферромагнитного резонанса в ферромагнитной пленке $\mathrm{La}_{0.7} \mathrm{Sr}_{0.3} \mathrm{MnO}_{3}$ и регистрировался в пленке $\mathrm{SrIrO}_{3}$, за счет обратного спинового эффекта Холла. Наблюдалось значительное увеличение полуширины спектра спинового тока и увеличение амплитуды спинового тока при охлаждении от комнатной температуры $(300 \mathrm{~K})$ до $135 \mathrm{~K}$.
\end{abstract}

Ключевые слова: ферромагнитный резонанс, гетероструктура, магнитная анизотропия, спиновый ток, обратный спиновый эффект Холла.

DOI: $10.21883 /$ FTT.2021.09.51259.26H

\section{1. Введение}

Оксиды $3 d$-переходных металлов (ТМО) имеют различные функциональные возможности, обусловленные наличием сильной электрон-электронной корреляции. Ярко выраженная спин-орбитальная связь привлекает внимание в последние годы в связи с появлением новых топологических состояний [1] и для приложений в спинтронике [2]. На границе $5 d$-TMOs с ферромагнетиком может происходить нарушение топологической симметрии в области границы и возникновение щели в спектре возбуждений, что может приводить к довольно сильным магнитоэлектрическим эффектам [3].

Чистый (без переноса заряда) спиновый ток - один из наиболее интересных и перспективных эффектов в спинтронике. Исследованию спинового тока посвящены множество публикаций как экспериментальных [4,5] так и теоретических [6,7]. В настоящей работе мы рассматриваем эффект возникновения спинового тока в двухслойных структурах, в которых ферромагнитный слой (ФМ) контактирует с нормальным немагнитным металлическим слоем (НМ). Когда ФМ-слой находится в условиях ферромагнитного резонанса (ФМР), то в направлении вдоль нормали к границе возникает спиновый ток, который соответствует передаче спинового момента от возбужденного ФМ к соседнему НМ $[7,8]$. В свою очередь в слое НМ спиновый ток преобразуется за счет обратного спинового эффекта Холл в электрический, который течет вдоль границы. Наличие спинового тока было продемонстрировано в различных комбинациях материалов, даже когда магнитный слой был изолятором (например, железо-иттриевый гранат), a нормальный слой - ферромагнетиком. Немагнит- ным материалом может быть переходный металл, полупроводник, проводящий полимер или топологический изолятор [9-15]. Иридат стронция $\mathrm{SrIrO}_{3}$ (SIO), являясь парамагнитным полуметаллом, обладает сильным спин-орбитальным взаимодействием, а его кристаллографические параметры близки к параметрам стронций допированного манганита $\mathrm{La}_{0.7} \mathrm{Sr}_{0.3} \mathrm{MnO}_{3}$ (LSMO). Благодаря этому обстоятельству, возможно создавать эпитаксиальные гетероструктуры SIO/LSMO с границей высокого качества, что позволяет надеяться на лучшие условия возникновения спинового тока по сравнению с гетероструктурой Pt/LSMO. Напряжение, вызванное спиновым током, удается зарегистрировать, измеряя напряжение на потенциальных выводах пленки SIO. В настоящей работе мы приводим результаты измерения температурной зависимости амплитуды напряжения, вызванного спиновым током, генерируемым на границе $3 d$ и $5 d$-переходных металлов в двуслойной гетероструктуpe SIO/LSMO.

\section{2. Экспериментальная часть}

\section{1. Образцы и методика эксперимента}

Тонкие пленки иридата стронция $\mathrm{SrIrO}_{3}$ и манганита $\mathrm{La}_{0.7} \mathrm{Sr}_{0.3} \mathrm{MnO}_{3}$ с толщинами 10 и $20 \mathrm{~nm}$, соответственно, осаждались на полированные монокристаллические подложки (110) $\mathrm{NdGaO}_{3}$ (NGO) размерами $5 \times 5 \mathrm{~mm}^{2}$ и толщиной $0.5 \mathrm{~mm}$. Рост эпитаксиальных пленок осуществлялся методом магнетронного напыления при температуре подложки $800^{\circ} \mathrm{C}$ в смеси газов $\mathrm{Ar}$ и $\mathrm{O}_{2}(3: 2)$ с давлением $0.3 \mathrm{mBar}$ при мощности ВЧ-генератора $50 \mathrm{~W}$ для манганита и $T=770^{\circ} \mathrm{C}$ при 
давлении $0.3 \mathrm{mBar}$ в смеси газов $\mathrm{Ar}$ и $\mathrm{O}_{2}(1: 2)$ и мощности ВЧ $40 \mathrm{~W}$ для иридата $\mathrm{SrIrO}_{3}$. Кристаллическая структура анализировалась с помощью рентгеновского дифрактометра. Из рентгеновских измерений выяснилось, что рост гетероструктуры осуществляется по методу „куб на куб“ со следующими эпитаксиальными соотношениями: (001)SIO \| (001)LSMO \| (110)NGO и [100]SIO $\|$ [100]LSMO $\|$ [001]NGO [16,17].

Для исследования температурной зависимости спинового тока использовались два варианта: в первом - самодельная полосковая линия (диапазон частот $1-3 \mathrm{GHz}$ ), а во втором - самодельный спектрометр магнитного резонанса с частотой $9.2 \mathrm{GHz}$. При измерении напряжения, вызванного спиновым током, использовалась амплитудная модуляция микроволнового сигнала. Напряжение на SIO-пленке регистрировалось синхронным детектором. Образец SIO/LSMO представляет собой полоску с электрическими серебряными контактами по краям для измерения напряжения. В первом варианте он располагался под полосковой линией в центре магнитного соленоида, задающего постоянное магнитное поле. Запись сигнала с пленки SIO проводилась при прохождении поля $H$ через линию ФМР с последующим накоплением. Для охлаждения ниже комнатной температуры использовался жидкий азот. Температура образца измерялась с помощью откалиброванного диода. Для получения угловой зависимости спектров ФМР и температурной зависимости амплитуды спинового тока использовался второй вариант с прямоугольным объемным резонатором $H_{102}$. Образец располагался посередине резонатора, в максимуме магнитной составляющей поля СВЧ. Компонента постоянного магнитного поля и магнитная составляющая поля СВЧ лежали в плоскости пленки. Внешнее постоянное магнитное поле вращалось в плоскости образца (угол $\varphi$ отсчитывался от одной из граней подложки) [18], а магнитная составляющая микроволнового поля была направлена вдоль измерения напряжения. При этом, конечно, менялся угол между переменной и постоянной компонентами магнитного поля, что сказывалось на амплитуде сигнала ФМР, но не мешало снимать угловые зависимости.

\section{2. Магнитные измерения}

На рис. 1 показана температурная зависимость резонансного поля и полуширины линии спектра напряжения, вызванного спиновым током, гетероструктуры SIO/LSMO, полученные на частоте $2.8 \mathrm{GHz}$ при условии, что внешнее магнитное поле направлено под углом $25^{\circ}$ к легкой оси плоскостной одноосной магнитной анизотропии. Таким образом, можно считать, что полученная температурная зависимость характеризует изменение эффективной намагниченности $M_{\text {eff }}$ образца. В этом приближении можно говорить, что уменьшение значения резонансного поля обусловлено увеличением $M_{\text {eff }}$ образца. Интересно отметить, что рост полуширины линии спектра напряжения, вызванного спиновым током,

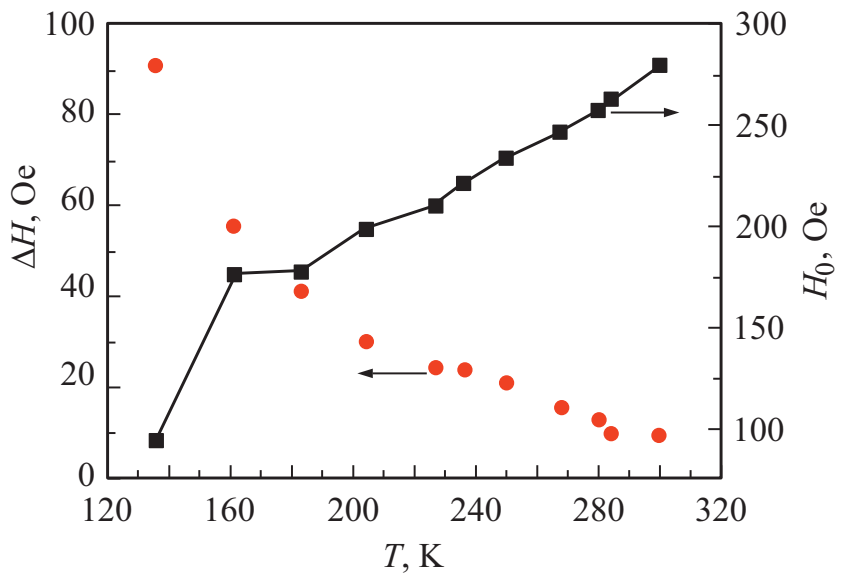

Рис. 1. Температурная зависимость поля максимума напряжения, вызванного спиновым током и полуширины спектра напряжения, вызванного спиновым током, гетероструктуры $\mathrm{SIO} / \mathrm{LSMO}$, снятые при частоте $f=2.8 \mathrm{GHz}$.

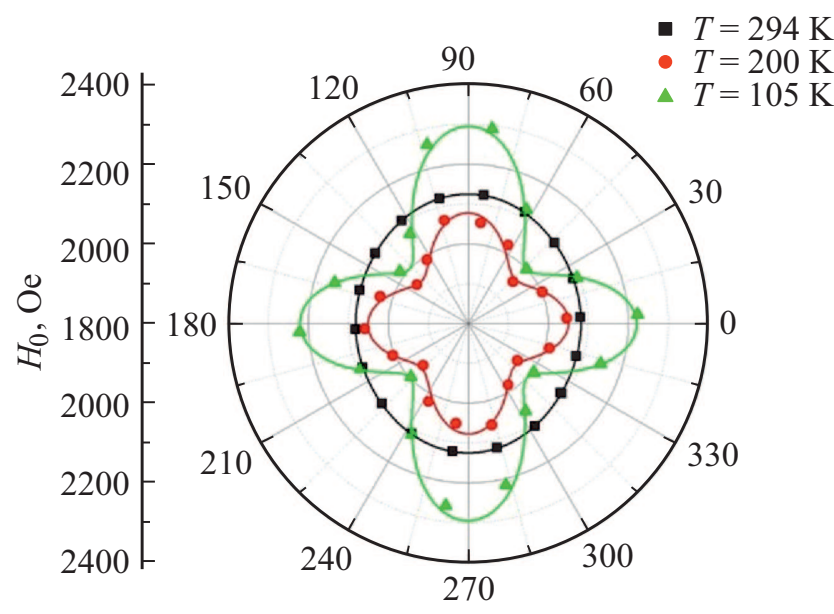

Рис. 2. Угловые зависимости резонансного поля ФМР при температурах 294, 200 и $105 \mathrm{~K}$, снятые на частоте $f=9.2 \mathrm{GHz}$

с понижением температуры качественно совпадает и численно превосходит рост полуширины спектра напряжения, вызванного спиновым током, для гетероструктуры Pt/LSMO/NGO [19]. А так как уширение линии обусловлено утечкой спинового момента из ФМ-слоя за счет спинового тока, то данный факт может косвенно свидетельствовать о том, что смешанная спиновая проводимость (spin mixing conductance) границы гетероструктуры SIO/LSMO при низких температурах превосходит смешанную спиновую проводимость границы гетероструктуры Pt/LSMO.

На рис. 2 показана угловая зависимость резонансного значения магнитного поля $H_{0}$ для гетероструктуры SIO/LSMO при трех температурах в зависимости от угла направления внешнего магнитного поля к легкой оси одноосной магнитной анизотропии, полученная в объемном резонаторе на частоте $9.2 \mathrm{GHz}$. На рис. 2 за 0 принято параллельное направление легкой оси плос- 
костной анизотропии и постоянного магнитного поля. Для определения параметров магнитной анизотропии на спектрометре Bruker была снята угловая зависимость резонансного поля. В этом случае постоянное и переменное магнитные поля были всегда направлены перпендикулярно друг другу и располагались в плоскости образца. Образец вращался вокруг оси, перпендикулярной плоскости. Изменение резонансного поля при изменении угла связано с наведенной подложкой одноосной магнитной анизотропией $\left(H_{u}\right)$ и двуосной кубической анизотропией $\left(H_{C}\right)$, обусловленной кристаллической решеткой слоя LSMO в гетероструктуре SIO/LSMO [18,20].

Из анализа угловых зависимостей резонансного поля $H_{0}$ при трех температурах (рис. 2) мы получаем следующие значения анизотропии: при $T=294 \mathrm{~K}$, $H_{u}=24.6 \mathrm{Oe}, H_{c}=3.9 \mathrm{Oе}$; при $T=200 \mathrm{~K} H_{u}=15.1 \mathrm{Oe}$, $H_{c}=63.8$ Ое и при $T=105 \mathrm{~K} H_{u}=42.5 \mathrm{Oe}, H_{c}=161.2 \mathrm{Oe}$.

\section{3. Спиновый ток}

На рис. 3 показано напряжение постоянного тока, измеренное вдоль образца с внешним полем приложенным под углом $25^{\circ}$ к легкой оси одноосной анизотропии слоя LSMO в условиях ФМР на частоте $2.6 \mathrm{GHz}$. Форма резонансной кривой содержит три вклада [5].

$V=V_{s p} L(H) \cos \varphi_{0}+\left[V_{A M R}^{\text {Sym }} L(H)+V_{A M R}^{\text {Antisym }} L^{\prime}(H)\right] \sin 2 \varphi_{0} \sin \varphi_{0}$

здесь линия поглощения ФМР $L(H)=(\Delta H)^{2} /\left[\left(H-H_{0}\right)^{2}\right.$ $\left.+(\Delta H)^{2}\right]$ - симметричная функция Лоренца с резонансным полем $H_{0}$ и полушириной $\Delta H . L^{\prime}(H)=\Delta H$ $\times\left(H-H_{0}\right) /\left[\left(H-H_{0}\right)^{2}+(\Delta H)^{2}\right]-$ антисимметричная

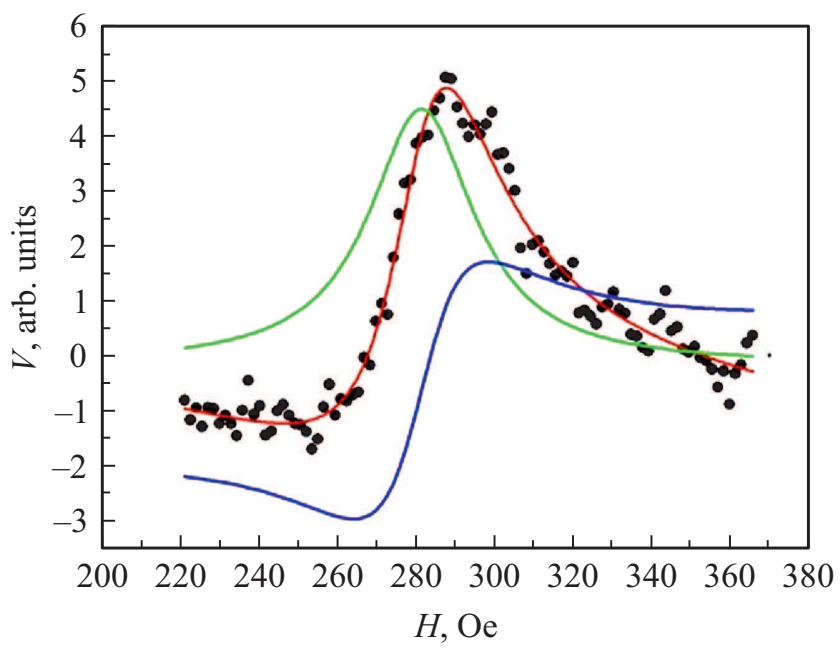

Pис. 3. Спектр напряжения, вызванного спиновым током, полученный при комнатной температуре на частоте $f=2.6 \mathrm{GHz}$. Закрашенные квадраты - экспериментальные точки, красная кривая - аппроксимация формулой (1), синяя кривая - антисимметричная часть анизатропного магнитосопротивления, зеленая кривая - сумма симметричных частей анизатропного магнитосопротвления и сигнала чистого спинового тока. (Рис. в цв. изображении см. в эл. версии журнала).

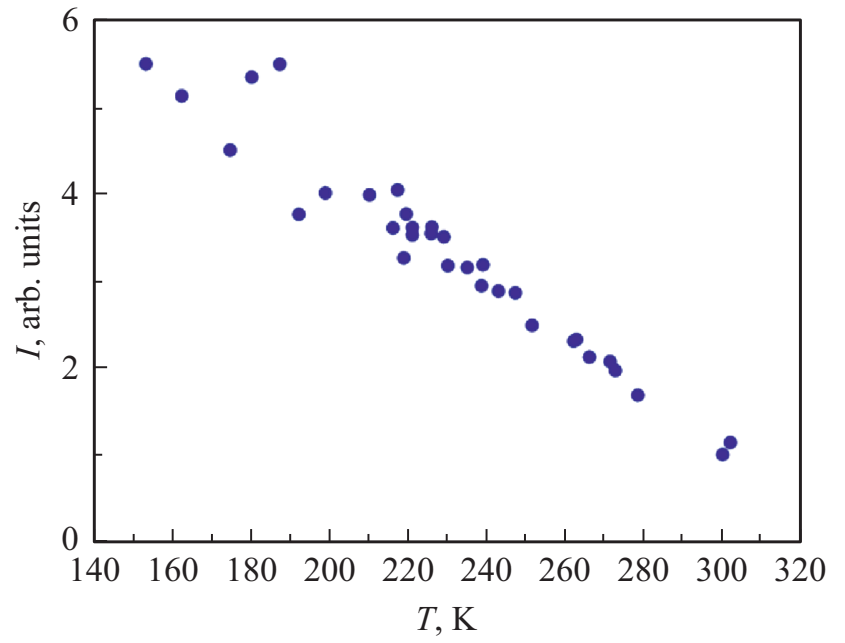

Рис. 4. Температурная зависимость электрического тока, вызванного спиновым током при частоте 9.2 GHz для SIO/LSMO.

функция, $\left(\varphi_{0}+\pi / 2\right)-$ угол между направлениями зарядового тока и равновесной намагниченностью LSMO [5]. Спектр напряжения, вызванного спиновым током, получен при комнатной температуре на частоте $f=2.6 \mathrm{GHz}$ и резонансном поле $H_{0}=284$ Ое. Полуширина Лоренцевой составляющей равна 16.6 Ое.

При измерениях температурной зависимости напряжения $V$, возникающего за счет спинового тока, внешнее поле $H$ было выставлено параллельно легкой оси одноосной магнитной анизотропии слоя LSMO. При такой конфигурации вклад сигнала анизотропного магнетосопротивления (АМР) минимален. Для того чтобы отделить температурную зависимость напряжения, вызванного чистым спиновым током, от АMP составляющей напряжения, а также для того, чтобы количественно учесть неоднородное уширение спектра напряжения, вызванного спиновым током при понижении температуры, мы воспользовались методом, изложенным в статье [19]. В результате, при учете факторов, не относящихся к генерации спинового тока, получилась зависимость, показанная на рис. 4. Исходя из рис. 4, можно сделать вывод о том, что с понижением температуры амплитуда напряжения, вызванного спиновым током в гетероструктуре SIO/LSMO в диапазоне 300-130 K, монотонно растет, что, в свою очередь, согласуется с предположением, высказанным ранее, о росте спиновой проводимости в данной гетероструктуре при низких температурах [21].

\section{3. Заключение}

В настоящей работе экспериментально были получены зависимости полуширины спектральной линии и амплитуды напряжения, вызванного спиновым током, от температуры при фиксированном положении магнитного поля относительно легкой оси одноосной плоскостной магнитной анизотропии. Результаты измерения свиде- 
тельствуют о монотонном росте амплитуды чистого спинового тока с понижением температуры в диапазоне $(300-130) \mathrm{K}$.

\section{Благодарности}

Авторы благодарны В.А. Ацаркину за обсуждение температурной зависимости синового тока.

\section{Финанасирование работы}

Работа выполнена в рамках государственного задания в ИРЭ им. В.А. Котельникова РАН и частичной поддержке проекта РФФИ 19-07-00143 и 19-07-00274.

\section{Конфликт интересов}

Авторы заявляют, что у них нет конфликта интересов.

\section{Список литературы}

[1] D. Xiao, W. Zhu, Y. Ran, N. Nagaosa, S. Okamoto. Nature Commun. 2, 596 (2011).

[2] E. Saitoh, M. Ueda, H. Miyajima, G. Tatara. Appl. Phys. Lett. 88, 182509 (2006).

[3] A. Manchon, H.C. Koo, J. Nitta, S.M. Frolov, R.A. Duine. Nature Mater. 14, 871 (2015).

[4] O. Mosendz, V. Vlaminck, J.E. Pearson, F.Y. Fradin, G.E.W. Bauer, S.D. Bader, A. Hoffmann. Phys. Rev. B 82, 214403 (2010).

[5] A. Azevedo, L.H. Vilela-Leao, R.L. Rodriguez-Suarez, A.F. Lacerda Santos, S.M. Rezende. Phys. Rev. B 83, 144402 (2011)

[6] Е.А. Караштин, ФТТ 61, 9, 1634 (2019).

[7] Y. Tserkovnyak, A. Brataas, G.E.W. Bauer. Phys. Rev. Lett. 88, 117601 (2002)

[8] A. Brataas, Y. Tserkovnyak, G.E.W. Bauer, B.I. Halperin Phys. Rev. B 66, 060404 (2002).

[9] F.D. Czeschka, L. Dreher, M.S. Brandt, M. Weiler, M. Althammer, I.M. Imort, G. Reiss, A. Thomas, W. Schoch, W. Limmer, H. Huebl, R. Gross, S.T.B. Goennenwein. Phys. Rev. Lett. 107, 046601 (2013).

[10] Y. Sun, H. Chang, M. Kabatek, Y.Y. Song, Z. Wang, M. Jantz, W. Schneider, M. Wu, E. Montoya, B. Kardasz, B. Heinrich, S.G.E. te Velthuis, H. Schultheiss, A. Hoffmann. Phys. Rev. Lett. 111, 106601 (2013).

[11] W. Zhang, M.B. Jungfleisch, W. Jiang, J. Sklenar, F.Y. Fradin, J.E. Pearson, J.B. Ketterson, A. Hoffmann. J. Appl. Phys. 117, 172610 (2015).

[12] C. Du, H. Wang, P.C. Hammel, F. Yang. J. Appl. Phys. 117, 172603 (2015)

[13] K. Ando, S. Takahashi, J. Ieda, H. Kurebayashi, T. Trypiniotis, C.H. Barnes W.S. Maekawa, E. Saitoh. Nature Mater. 10, 655 (2011).

[14] K. Ando, S. Watanabe, S. Mooser, E. Saitoh, H. Sirringhaus. Nature Mater. 12, 622 (2013).

[15] M. Jamali, J.S. Lee, J.S. Jeong, F Mahfouzi, Y. Lv, Z. Zhao, B.K. Nikolic, K.A. Mkhoyan, N. Samarth, J.P. Wang. Nano Lett. 10, 157126 (2015).
[16] Т.А. Шайхулов, Г.А. Овсянников, В.В. Демидов, Н.В. Андреев. ЖЭТФ. 156, 135 (2019)

[17] G.A. Ovsyannikov, T.A. Shaikhulov, K.L. Stankevich, Yu. Khaydukov, N.V. Andreev. Phys.Rev B 102, 14, 144401 (2020).

[18] V.V. Demidov, G.A. Ovsyannikov, A.M. Petrzhik, I.V. Borisenko, A.V. Shadrin, R.J. Gunnarsson. Appl. Phys. 113, 163909 (2013).

[19] В.А. Ацаркин, В.В. Демидов, Т.А. Шайхулов. ЖЭТФ 157, 2, $272(2020)$.

[20] В.В. Демидов, И.В. Борисенко, А.А. Климов, Г.А. Овсянников, А.М. Петржик, С.А. Никитов. ЖЭТФ 139, 943 (2011).

[21] V.A. Atsarkin, I.V. Borisenko, V.V. Demidov, T.A. Shaikhulov. J. Phys. D 51, 245002 (2018).

Редактор К.В. Емцев 